\title{
Dental aesthetics and self-esteem in adolescents
}

\author{
Ana Cristina Mafla, DDS, MPH ${ }^{1}$, Edwin Gerardo Luna, PsyD², \\ Nubia Rocío Sánchez, PsyD ${ }^{3}$, David Alexander Barrera ${ }^{4}$, Ginna Mabel Muñoz ${ }^{4}$
}

\section{SUMMARY}

Objective: The aim of this study was to investigate the relationship between dental aesthetics and self-esteem in adolescents.

Methods: The sample was 387 randomly selected high school adolescents between 13 and 16 years of age. A clinical examination to evaluate dental aesthetics was conducted using the Dental Aesthetic Index (DAI). Self-esteem was assessed with the Rosenberg's Self-esteem Scale. The statistical analysis included a descriptive analysis and means comparison, which was made through $t$-Student and ANOVA tests. DAI was correlated to Rosenberg's Self-esteem Scale with Spearman's rank correlation coefficient. The data collected was analyzed by using the SPSS program version 17.

Results: The mean DAI score was $34.2(\mathrm{SD}=14.2)$ and self-esteem was $22.6(\mathrm{SD}=4.6)$. The low socioeconomic status (SES) group had the highest levels of DAI and the lowest levels of self-esteem. A weak, but statistically significant, negative correlation was found between DAI scores and Rosenberg's self-esteem scale $(r=-0.1, p<0.05)$. According to age, in adolescents aged sixteen there was a slight correlation with both variables ( $>>0.05)$. Regarding gender, in female individuals a negative weak correlation $(r=-0.14, p<0.05)$ was observed. No statistically significant difference was shown among SES groups. Nevertheless, there was a positive slight correlation in the middle SES group ( $>>0.05$ ).

Conclusions: The outcomes generated by this investigation can improve our understanding of how the correlation between dental aesthetics and self-esteem may fluctuate because of the SES variability.

\section{Keywords: Aesthetics; Dental Aesthetic Index; Malocclusion; Self-esteem Rosenberg Scale;} Adolescent; Socioeconomic status.

Colomb Med. 2011; 42: 482-9

\section{Estética dental y autoestima en adolescentes}

\section{RESUMEN}

Objetivo: Investigar la relación entre estética dental y autoestima en adolescentes.

Métodos: La muestra de 387 adolescentes entre 13 y 16 años seleccionados aleatoriamente de los colegios de educación secundaria. Se realizó un examen clínico para evaluar la estética dental a través del Dental Aesthetic Index (DAI). La autoestima se valoró usando la Rosenberg's Self-esteem Scale. El análisis estadístico incluyó medidas descriptivas y una comparación de medias realizadas a través de las pruebas t-Student y ANOVA. El DAI se correlacionó con la Rosenberg Selfesteem Scale por medio del coeficiente de correlación de Spearman. Los datos recolectados se analizaron en el programa SPSS versión 17.

Resultados: La media de DAI fue 34.2(DE=14.2) y de autoestima de 22.6(DE=4.6). El grupo de estrato socio-económico (SES) bajo tuvo los niveles más altos de DAI y los más bajos de autoestima. Una pequeña pero significativa correlación negativa se encontró entre los niveles del DAI y la Rosenberg's Self-esteem Scale ( $\mathrm{r}=-0.1 ; \mathrm{p}<0.05)$. De acuerdo con la edad,

1. Dentistry Research Group Director, Dental School, Universidad Cooperativa de Colombia, Pasto, Colombia. e-mail:ana.mafla@campusucc.edu.co

2. Research Professor, Member of the Psicología y Salud Research Group, Deparment of Psychology, Universidad de Nariño, Pasto, Colombia. e-mail: lunaedwingerardo@gmail.com

3. Research Professor, Member of Medición Métodos e Instrumentos para la Investigación en Ciencias del Comportamiento Research Group, Universidad Nacional de Colombia, Bogotá, Colombia. e-mail: nrsanchezm@unal.edu.co

4. Dental School student, Universidad Cooperativa de Colombia, Pasto, Colombia. e-mail: davidbp28@hotmail.com mabis_m@hotmail.com

Received for publication February 16, 2010 Accepted for publication July 13, 2010 
los adolescentes de 16 años tuvieron una leve correlación en las dos variables ( $\mathrm{p}>0.05$ ). En relación con género, en mujeres se encontró una pequeña correlación negativa $(r=-0.14$; $\mathrm{p}<0.05)$. Ninguna correlación estadísticamente significativa se observó entre los grupos según estrato socioeconómico. Sin embargo, existió una leve correlación positiva en estrato socio-económico medio ( $\mathrm{p}>0.05$ ).

Conclusiones: Los resultados obtenidos por esta investigación pueden mejorar el entendimiento de cómo la correlación de estética dental y autoestima podría fluctuar debido a la variabilidad del SES.

Palabras clave: Estética; Índice de estética dental; Maloclusión; Autoestima; Escala Rosenberg; Adolescente; Clase social.

Colomb Med. 2011; 42: 482-9

Aesthetics is conventionally identified in academia with the philosophy of art and beauty. But despite the considerable consensus on such definition, the concept of aesthetics remains deeply ambiguous, complex, and essentially contested ${ }^{1}$. The field of aesthetics has emerged from early stages and different species ${ }^{2}$. Moreover, theories on beauty have a very long history. What makes something or someone beautiful; whether beauty is a property of the object/person or rather rests in the eye of the beholder are questions that have occupied thinkers since the ancient Greeks ${ }^{3}$. Currently, in diverse environments, aesthetics has been recognized through personal appearance influencing different aspects, such as, job, behavior, self-esteem, and social connection ${ }^{4}$. Dentistry also has been part of this phenomenon. Nowadays, we can frequently observe new treatments to improve dental aesthetics, such as restorations or orthodontics.

Young people aged 10 to 19 currently constitute a demographic bulge. They are the largest age group in the world, making up close to $20 \%$ of the 6.5 billion world population estimated in 2005, 85\% of whom live in developing countries and account for about one-third of those countries national populations ${ }^{5}$. In the adolescence stage, individuals undergo extensive physical, psychological, emotional, and personality transformations, which determine an identity that will influence on their future. During this phase of life, particularly in middle adolescence, individuals are extremely concerned with appearance and body, feelings of strangeness about one's self and body, lower self- esteem $^{6}$, lowered opinion of and withdrawal from parents, efforts to make new friends, strong emphasis on the new peer group, sexual attractiveness, or feelings of love and passion.

According to physical appearance, during adolescence the mouth is perhaps an important body part. Apparently, adolescents' own perception of the severity of their malocclusion was an important contributing factor to the self-concept and self-esteem levels ${ }^{7}$. However, other studies show a weak correlation in adolescents who received orthodontic treatment with higher levels of self-esteem ${ }^{8}$. Given that adolescence is a critical stage, the self-esteem levels in these individuals should be an important matter in health sciences. Neurophysiological and brain imaging studies have demonstrated brain reorganization during adolescence coincident with the onset of puberty, which may make adolescents more sensitive to experiences that affect their judgment ${ }^{9}$. In this sense, it has been revealed that there is a strong correlation among low self-esteem and social problems, and risk behaviors, such as, smoking, alcohol consumption, psychoactive substance use ${ }^{10}$, along with having few reasons for living ${ }^{11}$. Although it is assumed that having a harmonious smile may increase levels of self-esteem in adolescents and, hence, their ability to interact appropriately in society, this relationship has not been measured in our city yet. The influence of dental aesthetics on self-esteem may fluctuate according to some socio-cultural or economic aspects. For these reasons, the purpose of this research is to examine the relationship between dental aesthetics and adolescents' self-esteem in individuals from San Juan de Pasto, Nariño in Colombia. New knowledge in this area will help to develop and test interventions in dentistry and psychology to promote physical and psychological well-being in young people and counteract risks associated with this developmental stage.

\section{METHODOLOGY}

Study design and participants. The investigation was conducted as a correlation study. This study was authorized by the Health Sciences Ethics Committee at Universidad Cooperativa de Colombia, Pasto (Act $\mathrm{N}^{\circ}$ CECS03-08), and all the parents of the students recruited signed an informed consent letter. A total of 387 high school individuals between 13 and 16 years of age were 
Table 1

The Dental Aesthetic Index (DAI)

\begin{tabular}{llcc}
\hline $\mathbf{N}^{\circ}$ & \multicolumn{1}{c}{ Traits } & Coefficient & Rounded weight \\
\hline 1 & Missing visible teeth, incisors, canines, and premolars $(\leq 1)$ & 5.76 & 6 \\
2 & Crowding in the incisal segments of the arch $(0=0,1=1-5 \mathrm{~mm}, 2 \geq 5 \mathrm{~mm})$ & 1.15 & 1 \\
3 & Spacing in the incisal segment of the $\operatorname{arch}(0=0,1=1-5 \mathrm{~mm}, 2 \geq 5 \mathrm{~mm})$ & 1.31 & 1 \\
4 & Diastema (mm) & 3.13 & 3 \\
5 & Anterior irregularity for upper teeth $(\mathrm{mm})$ & 6.75 & 7 \\
6 & Anterior irregularity in the lower arch $(\mathrm{mm})$ & 1.34 & 1 \\
7 & Anterior maxillary overjet (mm) & 1.62 & 2 \\
8 & Anterior mandibular overjet (reverse overjet) (mm) & 3.68 & 4 \\
9 & Vertical anterior open bite (mm) & 3.69 & 4 \\
10 & Antero-posterior molar relationship (0=Angle Class I, & & \\
& 1=Angle Class II, and 2=Angle Class III) & 2.69 & 3 \\
\hline & Constant & 13.36 & 13 \\
\hline
\end{tabular}

selected from a group of 20,175 students reported by the Council Office of the Secretary of Education. The stratified sample size was calculated to have a $95 \%$ level of confidence. The sample was obtained through proportional allocation according to ages and gender based on the following values: $27.8 \%$ (13 years-old), $26.8 \%$ (14 years-old), 24.8\% (15 years-old), and 20\% (16 years-old); gender was taken through a male to female ratio of $1: 1$. The study was carried out at Champagnat, San Francisco de Asís and San Juan Bosco high schools in San Juan de Pasto, Nariño, Colombia from September 2008 to April 2009. Students were excluded from the study if they wore orthodontic appliances or if they had a history of previous orthodontic treatment. During the data collection process, researchers corroborated the socio-economic status (SES) in the high school offices. An ordinal scale of three categories was available (low, medium, and high SES). The data collection was divided into two parts, consisting of evaluating dental aesthetics and selfesteem.

Dental Aesthetic Index (DAI).Dental aesthetics was measured using the DAI validated in different ethnic groups ${ }^{12}$. The DAI consisted of 10 occlusal traits related to dentofacial anomalies according to the three dentition components, i.e., spacing, crowding, and occlusion. To calculate the DAI score, each trait was multiplied by a previously reported weight ${ }^{13}$ and a constant of 13 was added to obtain a final DAI score for each adolescent (Table 1). Higher DAI scores indicated lower levels of dental aesthetics. DAI also has different parameters, values $\leq 25$ represent normal or minor malocclusions with no or slight treatment needed; values from 26-30 represent definite malocclusions with treatment elective. Measurements from 31-35 reveal severe malocclusions with treatments highly desirable, and values $\geq 36$ evidence very severe or handicapping malocclusions with treatment considered mandatory. A clinical examination was performed at the medical offices in the high schools by two calibrated examiners. The calibration process was conducted prior to the study to guarantee reliable data collection. The Cohen's Kappa coefficient was used for these analyses and the levels of inter- and intra-examiner agreement were determined as follows:

1. For intra-examiner reliability, 14 dental students volunteers were evaluated consecutively two times by each examiner after an interval of 20 minutes. The average of Cohen's Kappa coefficient for the ten DAI components was 0.82 and 0.83 respectively.

2. For inter-examiner agreement, 39 adolescents ( $10 \%$ out of $100 \%$ sample) from the high schools selected were evaluated once by the observers. The agreement average of these DAI traits between both examiners through the Cohen's Kappa coefficient was 0.79.

Self-esteem. Self-esteem was assessed by using Rosenberg's self-esteem scale (RSE) ${ }^{14}$. This scale is a 10-item Likert scale with items answered on a four- 
Table 2

The Rosenberg Self-Esteem Scale (RSE)

\begin{tabular}{ll}
\hline $\mathbf{N}^{\circ}$ & \multicolumn{1}{c}{ Question } \\
\hline 1 & On the whole, I am satisfied with myself \\
2 & At times, I think I am no good at all \\
3 & I feel that I have a number of good qualities \\
4 & $\begin{array}{l}\text { I am able to do things as well as most other } \\
\text { people }\end{array}$ \\
5 & I feel I do not have much to be proud of \\
6 & I certainly feel useless at times \\
7 & $\begin{array}{l}\text { I feel that I am a person of worth, at least on } \\
\text { an equal plane with others }\end{array}$ \\
8 & I wish I could have more respect for myself \\
9 & $\begin{array}{l}\text { All in all, I am inclined to feel that I am a } \\
\text { failure }\end{array}$ \\
10 & I take a positive attitude toward myself \\
\hline
\end{tabular}

Rating: Each item is rated from 0 (do not agree at all) to 3 (completely agree). The items 2, 5, 6, 8, and 9 have to be reversed prior to calculating the sum score.

point scale. Each item was rated from 1 (do not agree at all) to 4 (completely agree). The points assessed were «strongly disagree», «disagree», «agree», and «strongly agree» (Table 2). Higher RSE scores indicate higher levels of self-esteem.

Statistical analysis. The data were analyzed statistically with the Statistical Package for Social Sciences (version 17, SPSS, Chicago, IL, USA). The distribution frequency and means were calculated by descriptive analysis and central tendency and variability measurements. The $t$ test was utilized to determine the difference between the means of the DAI or Rosenberg's Self-esteem Scale (RSE) and gender. In addition, the differences among DAI or RSE and variables like age and SES were calculated via ANOVA test. Spearman's rank correlation coefficient, based on the original values, was used for the total scores to assess the linear association of the more continuous total scores. In this sense, this coefficient was used to investigate the correlation between DAI and RSE and observe the trend by age, gender, and SES adjustment.

\section{RESULTS}

The mean DAI score was $34.2(\mathrm{SD}=14.2)$ and the mean self-esteem score was $22.6(\mathrm{SD}=4.6)$. Regarding age, gender, and socioeconomic status, no statistically significant differences were noted between DAI and

Table 3

Dental Aesthetic Index (DAI) score and Rosenberg's Self-esteem Scale (RSE) means by age, gender and SES in 387 adolescents from Pasto, Nariño, Colombia

\begin{tabular}{|c|c|c|c|c|c|}
\hline \multirow[t]{2}{*}{ Variable } & \multirow[t]{2}{*}{ Observed } & \multicolumn{2}{|c|}{ DAl score } & \multicolumn{2}{|c|}{ RSE score } \\
\hline & & Mean & SD & Mean & SD \\
\hline \multicolumn{6}{|l|}{ Age } \\
\hline 13 & 108 & 34.80 & 14.02 & 21.78 & 4.72 \\
\hline 14 & 102 & 33.47 & 15.23 & 22.72 & 4.38 \\
\hline 15 & 96 & 34.31 & 13.01 & 23.28 & 5.03 \\
\hline 16 & 81 & 34.38 & 15.07 & 23.17 & 4.26 \\
\hline \multicolumn{6}{|l|}{ Gender } \\
\hline Male & 192 & 35.31 & 15.13 & 22.47 & 4.65 \\
\hline Female & 195 & 33.19 & 13.37 & 22.91 & 4.63 \\
\hline \multicolumn{6}{|l|}{ SES* } \\
\hline Low & 129 & 42.64 & 16.07 & 20.53 & 4.74 \\
\hline Middle & 129 & 30.68 & 12.99 & 23.65 & 4.40 \\
\hline High & 129 & 29.40 & 9.01 & 23.89 & 4.01 \\
\hline
\end{tabular}

${ }^{*} \mathrm{p}<0.01$ 
Table 4

Bivariate correlation between

Dental Aesthetic Index (DAI) score and

Rosenberg's Self-esteem Scale (RSE)

by age, gender, and SES adjustment

\begin{tabular}{lcll}
\hline Variable & Observed & r Spearman & $\mathbf{p}$ \\
\hline Age & & & \\
13 & 108 & -0.09 & 0.17 \\
14 & 102 & -0.08 & 0.18 \\
15 & 96 & -0.08 & 0.22 \\
16 & 81 & -0.14 & 0.09 \\
Gender & & & \\
Male & 192 & -0.07 & 0.14 \\
Female & 195 & -0.14 & $0.02^{\star}$ \\
SES & & & \\
Low & 129 & -0.00 & 0.49 \\
Middle & 129 & 0.11 & 0.10 \\
High & 129 & -0.01 & 0.42 \\
\hline
\end{tabular}

${ }^{*} p<0.05$

self-esteem in terms of age and gender. Nevertheless, with respect to SES differences were noted $(\mathrm{p}<0.01)$ (Table 3). In relation to DAI, 124 subjects (32\%) had normal o minimal malocclusion, 59 (15.2\%) showed definite malocclusion, $80(20.7 \%)$ revealed severe malocclusion, and 124 (32\%) had very severe malocclusion. Severe and very severe malocclusion was present in $52.7 \%$ of the adolescents studied. In relation to age, very severe malocclusion was observed, thus: the group of subjects thirteen years of age presented 36 cases (33.3\%), the group of fourteen-year olds showed 30 (29.4\%), the fifteen-year olds had 32 (33.3\%), and the sixteen-year olds presented 26 (32.1\%). According to gender, very severe malocclusion was higher in males with 70 (36.5\%) cases than in females with 54 (27.7\%) cases. In relation to SES, the percentage of individuals with very severe malocclusion increased inversely proportional to SES, the low SES group had 75 cases (58.1\%), the middle SES individuals showed 28 (22.6\%), and the high SES subjects presented 21 cases $(16.3 \%)$; $(\mathrm{p}<0.01)$.

Regarding adolescents' self-esteem, 112 (28.9\%) cases had low self-esteem; middle self-esteem was observed in 158 (40.8\%) subjects and 117 (30.2\%) adolescents presented high self-esteem. With respect to age, low self-esteem $(\mathrm{p}<0.01)$ was noted in $43(39.8 \%)$ cases of thirteen-year olds, 29 (28.4\%) cases of fourteenyear olds, 25 (26\%) cases of fifteen-year olds, and 15 (18.5\%) cases of sixteen-year old adolescents. According to gender, 62 (32.3\%) males and 50 (25.6\%) females had low self-esteem. In relation to SES, low SES adolescents showed 56 (43.4\%) cases, the middle SES group had $30(23.3 \%)$ cases, and the high SES group presented $26(20.2 \%)$ cases $(\mathrm{p}<0.01)$ with low self-esteem. In Table 4, a weak but statistically significant, negative, correlation could be observed between DAI scores and the self-esteem scale ( $\mathrm{r}=-0.1$, $\mathrm{p}<0.05)$. According to age, in adolescents aged sixteen, there was a slight correlation for both variables, however it was statistically insignificant. Regarding gender and SES, a negative weak but significant correlation was found for females, and there was a positive slight correlation for the middle SES group; although no statistically significant difference was reported.

Given that SES influences the main outcomes, we controlled the group of sixteen-year olds and females for it. We found a positive correlation between DAI and the self-esteem scale in low SES sixteen-year-old adolescents ( $r=0.27, \mathrm{p}>0.05)$; however, there were no correlations in the other SES levels. Furthermore, a negative weak correlation for high SES females ( $\mathrm{r}=-$ $0.2, \mathrm{p}>0.05$ ) was observed.

\section{DISCUSSION}

Self-esteem refers to a person's general sense of worth or acceptance; it is recognized as playing a critical role in mental health and psychopathology such as symptoms of depression ${ }^{15}$. However, there is a lack of understanding about how individuals evaluate themselves, especially during adolescence ${ }^{16}$. Adolescence is a stage of life which offers the potential to prevent from both current impairment and future illness, and promoting successful development into productive adulthood. In the pursuit of these goals, understanding risk factors is imperative to identify adolescents who might need early intervention.

In current society, adolescents have a body and beauty's cult and it seems to be an emerge feeling ${ }^{17}$. In this sense, dental aesthetics is apparently a concept of growing importance in recent years. For this reason, 
individuals may consider that having an imperfect smile might be a cause of contempt and discriminatory attitudes from others. The DAI provides an assessment of the relative social acceptability of the dental appearance based on the public's perception of dental aesthetics. The index is useful in predicting handicapping and non-handicapping malocclusion ${ }^{18}$, which is related to dental aesthetics.

The study shows an analysis of the relationship of dental aesthetics and self-esteem in adolescents from Pasto, Nariño in Colombia. DAI was selected for this study because this index measures both malocclusion and aesthetics aspects. In addition, DAI is a crosscultural index by the World Health Organization (WHO) and because of its relative simplicity and high reliability, it has become a widely used index ${ }^{19}$. Also, we use the Rosenberg's self-esteem scale (RSE). This scale is a brief and unidimensional measure of global self-esteem. Additionally, studies have been conducted to investigate the validity and reliability of the RSE ${ }^{20}$ in adolescents. It is the most extensively used scale to measure global self-esteem in research studies.

As a result of this investigation, we found that SES influences both, DAI and self-esteem scale mean comparisons. However, we observed controversial findings, since there was a significant, negative, weak correlation (-0.1) between DAI and the self-esteem scale, but this association no longer exists after controlling it for SES. This outcome suggests that SES has a strong influence on the correlation between dental aesthetics and self-esteem.

Self-esteem and SES are two psychological and sociological variables that may be linked. Because of SES is an indicator of status within social groups and also allows access to every single thing that creates satisfaction in the life, changes in self-esteem result from changes in SES ${ }^{21}$. If an individual aspires to succeed in terms of social status and wealth and achieves these goals, elevated self-esteem should result. Conversely, the individual who does not achieve social status may suffer from lowered self-esteem. In addition, according to the reflected appraisals model, we internalize others' perceptions of ourselves. This process is sometimes referred to as the «looking-glass self'» or the «internalization of stigma» ${ }^{22}$. This paradigm applies to SES because SES influences on the way others treat us and, thus, it is eventually reflected in our self-esteem.
For the interpretation of these results we assumed a thesis in which self-esteem is a positive or negative attitude to oneself, which results from comparing our self-concept to our ideal self-concept. In this sense, when there are differences between both, problems with self-esteem arise, i.e., a negative attitude to oneself. It is suggested that current influences from the media may be associated to the development of selfesteem, because it establishes physical appearance stereotypes that increase the ideal self-concept, which is compared to the real self-concept. Although, these messages about the ideal individual form are transmitted through a variety of means, mass media may be one of the most important ${ }^{23}$.

Mass media is present in the lives of adolescents via television, movies, magazines, and advertisements. Consistent with the last statement, a study by Kim and Lennon $^{24}$ in 2007 suggests a significant positive relationship between exposure to fashion or beauty magazines and overall appearance dissatisfaction that may lead to low self-esteem. To clarify our results according to how SES influences this correlation, we believe there is an obvious connection between one's SES and one's personal sense of worth in two ways. First, higher SES individuals have the opportunity to get more information, services and material sources to improve their physical appearance, which decreases the difference between a real self-concept and an ideal self-concept. In other words, higher SES adolescents may have a similar real self-concept and ideal selfconcept in relation to dental aesthetics. Second, we have found other interesting phenomena to explain for individuals in lower SES. Even though they do not have the possibility of getting the same things to improve their physical appearance as higher SES adolescents do, they do not seem to have problems with the difference between their real self-concept and ideal self-concept. It may be because they do not have social pressures from their family or peers, because they fit in their groups of reference since almost all the subjects might have the same dental problems. In this sense, lower SES individuals have social acceptance in those reference groups and because of this, they may not have a lower self-esteem correlated to dental aesthetics.

Furthermore, the outcomes revealed a negative and slight correlation between DAI scores and self-esteem in 16-year-old individuals ( $\mathrm{r}=-0.14, \mathrm{p}>0.05)$. We also 
found a positive slight correlation in low SES 16-yearold adolescents ( $\mathrm{r}=0.27, \mathrm{p}>0.05$ ). Regarding gender, females showed a negative, weak but significant correlation between dental aesthetics and self-esteem $(\mathrm{r}=-0.14, \mathrm{p}<0.05)$. In addition, a correlation of -0.2 ( $>0.05$ ) was observed for high SES female adolescents.

These findings strengthen the concept of self-esteem as a construct not only in terms of individual cognitive processes, but a construct that is significantly affected by the social and material context within which a person is immersed. From this perspective, cognitive processes play a very important mediating role, being inappropriate to attribute causal properties on behavior patterns that are designated under the category of selfesteem. Assuming the last position has important implications over the actions we could design to intervene in the self-esteem of young subjects and other individuals. Specifically, we should shift the focus of clinical attention just on «mind», but we ought to study the context within which individuals establish and maintain their behavioural interactions.

In addition, a report by Raevuori et al. ${ }^{25}$ in 2007 reported that because longitudinal studies suggested both continuity and change in patterns of self-esteem throughout adolescence, it is particularly important to understand the factors contributing to self-esteem at this age and to examine potential gender differences in stability and change. They found that the genetic and environmental determinants of age-to-age correlation in self-esteem differ by gender. In boys, it was largely due to genetic influences, suggesting a substantial biological basis to the development of self-esteem in adolescent males. In girls, genetic and environmental factors shared by a twin pair explained most of the correlation between self-esteem assessed three years apart; the contribution of unique environment was almost the same as in boys.

\section{CONCLUSION}

This study showed a weak correlation between dental aesthetics and adolescents' self-esteem in our community. Besides, the outcomes also generated by this investigation can improve our understanding of how the dental aesthetics and self-esteem correlation may fluctuate because of socioeconomic status variability. For this reason, there is growing in-depth interest on this dynamic because it could have a vast field for future research work. Further, there is a need to determine appropriate assessment methods to study other variables that may be associated with dental aesthetics and self-esteem, such as, peers and family relationships, links between real and ideal self-concept, and the media.

Conflict of interest. The authors have no financial relationship with Comité Nacional para el Desarrollo de la Investigación (CONADI), which sponsored the research. We declare having no conflicts of interest that may be inherent in this submission.

\section{ACKNOWLEDGEMENTS}

The authors thank the high schools principals for permitting the data collection, and are very grateful to the psychology students, Cristhian Camilo Benavides Acosta and Oscar Orlando David Ceballos, for their support in self-esteem diagnoses of the adolescents. This study was supported by the Comité para el Desarrollo de la Investigación (CONADI), Universidad Cooperativa de Colombia, Pasto, Colombia.

\section{REFERENCES}

1. Shusterman R. The aesthetic. Theory, Culture \& Society. 2006; 23: 237-52.

2. Chaine AS, Lyon BE. Adaptive plasticity in female mate choice dampens sexual selection on male ornaments in the Lark Bunting. Science. 2008; 319: 459-62.

3. Holliday R, Sánchez Taylor J. Aesthetic surgery as false beauty. Feminist Theory. 2006; 7: 179-95.

4. Park LE, Maner JK. Does self-threat promote social connection? The role of self-esteem and contingencies of selfworth. J Pers Soc Psychol. 2009; 96: 203-17.

5. Ritcher LM. Studying adolescence. Science. 2006; 312: 190205 .

6. Williams JM, Currie JE. Self-esteem and physical development in early adolescence: pubertal timing and body image. J Early Adolescence. 2000; 20: 129-49.

7. Rivera SM, Hatch JP, Rugh JD. Psychological factors associated with orthodontic and orthognathic surgical treatment. Semin Orthod. 2000; 6: 259-69.

8. Badran SA. The effect of malocclusion and self-perceived aesthetics on the self-esteem of a sample of Jordanian adolescents. Eur J Orthod. 2010; 3: 638-44.

9. Blakemore SJ, Choudhury S. Development of the adolescent brain: implications for executive function and social cognition. J Child Psychol Psychiatry. 2006; 47: 296-312.

10. Miller P, Plant M, Choquet M, Ledoux S. Cigarettes, alcohol, 
drugs and self-esteem: a comparison of 15-16-year-olds from France and the UK. J Substance Use. 2002; 7: 71-7.

11. Merwin RM, Ellis JB. Children's reasons for living, selfesteem, and violence. Arch Suicide Res. 2004; 8: 251-61.

12. Cons NC, Jenny J. Comparing perceptions of dental aesthetics in the USA with those in eleven ethnic groups. Int Dent $J$. 1994; 44: 489-94.

13. Cons NC, Jenny J, Kohout FJ. DAI: The Dental Aesthetic Index. Iowa City: College of Dentistry, University of Iowa; 1986.

14. Rosenberg M. Society and the adolescent self-image. Princeton: Princeton University Press; 1965. 326 p.

15. Lincoln TM, Mehl S, Ziegler M, Kesting ML, Exner C, Rief W. Is fear of others linked to an uncertain sense of self? The relevance of self-worth, interpersonal self-concepts, and dysfunctional beliefs to paranoia. Behav Ther. 2010; 4: 18797.

16. Polce-Lynch M, Myers BJ, Kliewer W, Kilmartin C. Adolescent self-esteem and gender: exploring relations to sexual harassment, body image, media influence, and emotional expression. J Youth Adolescence. 2001; 30: 225-44.

17. Lopes de Souza PM. Body-image and obesity in adolescence: A comparative study of social-demographic, psychological, and behavioral aspects. Spanish J Psychol. 2008; 11: 551-63.

18. Jenny J, Cons NC, Kohout FJ, Jakobsen J. Predicting handicapping malocclusion using the Dental Aesthetic Index (DAI). Int Dent J. 1993; 43: 128-32.

19. Onyeaso CO. Orthodontic treatment need of Nigerian outpatients assessed with the Dental Aesthetic Index. Aust Orthod J. 2004; 20: 19-23.

20. Hagborg WJ. The Rosenberg self-esteem scale and Harter's self-perception profile for adolescents: a concurrent validity study. Psychol Sch. 1993; 30: 132-6.

21. Orth U, Trzesniewski KH, Robins RW. Self-esteem development from young adulthood to old age: a cohortsequential longitudinal study. J Pers Soc Psychol. 2010; 98: 645-58.

22. Twenge JM, Campbell WK. Self-esteem and socioeconomic status: a meta-analytic review. Pers Soc Psychol Rev. 2002; 6: 59-71.

23. Bardone-Cone AM, Cass KM, Ford JA. Examining body dissatisfaction in young men within a biopsychosocial framework. Body Image. 2008; 5: 183-94.

24. Kim JH, Lennon SJ. Mass media and self-esteem, body image, and eating disorder tendencies. Clothing Textiles Res J. 2007; 25: 3-23.

25. Raevuori A, Dick DM, Keski-Rahkonen A, Pulkkinen L, Rose $\mathrm{RJ}$, Rissanen A, et al. Genetic and environmental factors affecting self-esteem from age 14 to 17: a longitudinal study of Finnish twins. Psychol Med. 2007; 37: 1625-33. 